\title{
Aldehyde dehydrogenase is used by cancer cells for energy metabolism
}

Joon Hee Kang ${ }^{1,8}$, Seon-Hyeong Lee ${ }^{1,8}$, Dongwan Hong ${ }^{2}$, Jae-Seon Lee ${ }^{1}$, Hee-Sung Ahn ${ }^{3,4}$, Ju-Hyun Ahn ${ }^{5,6}$, Tae Wha Seong ${ }^{1}$, Chang-Hun Lee ${ }^{1}$, Hyonchol Jang ${ }^{1}$, Kyeong Man Hong ${ }^{7}$, Cheolju Lee ${ }^{3,4}$, Jae-Ho Lee $e^{5,6}$ and Soo-Youl Kim ${ }^{1}$

We found that non-small-cell lung cancer (NSCLC) cells express high levels of multiple aldehyde dehydrogenase (ALDH) isoforms via an informatics analysis of metabolic enzymes in NSCLC and immunohistochemical staining of NSCLC clinical tumor samples. Using a multiple reaction-monitoring mass spectrometry analysis, we found that multiple ALDH isozymes were generally abundant in NSCLC cells compared with their levels in normal IMR-90 human lung cells. As a result of the catalytic reaction mediated by ALDH, NADH is produced as a by-product from the conversion of aldehyde to carboxylic acid. We hypothesized that the NADH produced by ALDH may be a reliable energy source for ATP production in NSCLC. This study revealed that NADH production by ALDH contributes significantly to ATP production in NSCLC. Furthermore, gossypol, a pan-ALDH inhibitor, markedly reduced the level of ATP. Gossypol combined with phenformin synergistically reduced the ATP levels, which efficiently induced cell death following cell cycle arrest.

Experimental \& Molecular Medicine (2016) 48, e272; doi:10.1038/emm.2016.103; published online 25 November 2016

\section{INTRODUCTION}

Although tyrosine kinase inhibitor therapy achieves higher objective response rates and longer remissions in lung cancer, relapses occur after 10-14 months owing to drug resistance. ${ }^{1,2}$ Therefore, understanding the mechanisms that underlie the biology of non-small-cell lung cancer (NSCLC) cells may provide a chance to improve therapeutic approaches by targeting metabolic enzymes involved in this drug resistance. Therefore, we explored changes in the expression of metabolic enzymes in NSCLC using a bioinformatics analysis. Our analysis revealed that aldehyde dehydrogenase isoforms (EC 1.2.1.3, ALDH) were upregulated in patients with lung adenocarcinoma (LUAD). Several reports have demonstrated an association between ALDH and clinical factors associated with cancer stemness in NSCLC. Survival analyses have revealed that ALDH1L1-positive patients have shorter overall survival rates than ALDH1L1-negative patients. ${ }^{3,4}$ Furthermore, a xenograft model has been used to show that
ALDH1A1-positive NSCLC cells are 100 times more tumorigenic than ALDH1A1-negative NSCLC cells. ${ }^{3}$ Although ALDH1A1- and ALDH3A1-positive tumors are considered to be malignant, the specific role of ALDH in the growth and survival of NSCLC remains unclear.

As a result of the reaction catalyzed by ALDH, NADH is produced from the conversion of aldehyde to carboxylic acid. Here, we investigated the expression of multiple ALDH isoforms in NSCLC, and we tested the role of ALDH in NSCLC to determine whether the NADH produced by ALDH may be a reliable energy source for ATP production in NSCLC. Furthermore, we assessed the effect of gossypol, a pan-ALDH inhibitor, on ATP production and cell death in NSCLC.

\section{MATERIALS AND METHODS}

mRNA profiling of LUAD metabolic targets

Gene expression data from RNA sequencing of patients with LUAD were collected from The Cancer Genome Atlas. ${ }^{5}$ Paired sequencing data consisting of matched cancerous and normal tissues were

\footnotetext{
${ }^{1}$ Cancer Cell and Molecular Biology Branch, National Cancer Center, Research Institute, Goyang, Gyeonggi-do, Republic of Korea; ${ }^{2}$ Cancer Immunology Branch, National Cancer Center, Research Institute, Goyang, Gyeonggi-do, Republic of Korea; ${ }^{3}$ Center for Theragnosis, Biomedical Research Institute, Korea Institute of Science and Technology, Seoul, Republic of Korea; ${ }^{4}$ Department of Biological Chemistry, University of Science and Technology, Daejeon, Republic of Korea; ${ }^{5}$ Department of Biochemistry and Molecular Biology, Ajou University School of Medicine, Genomic Instability Research Center, Suwon, Korea; ${ }^{6}$ Department of Biomedical Sciences, The Graduate School, Ajou University, Suwon, Korea and ${ }^{7}$ Omics Core Laboratory, National Cancer Center, Research Institute, Goyang, Republic of Korea

8These authors contributed equally to this work.

Correspondence: Dr S-Y Kim, Cancer Cell and Molecular Biology Branch, National Cancer Center, Research Institute, 323 IIsan-ro, Ilsandong-gu, Goyang, Gyeonggi-do 410-769, Republic of Korea.
}

E-mail: kimsooyoul@gmail.com

Received 20 April 2016; revised 16 June 2016; accepted 29 June 2016 
normalized based on RNA sequencing expression estimates via expectation maximization using a custom-made script. To explore metabolic targets associated with cancer, we selected metabolic genes based on the Kyoto Encyclopedia of Genes and Genomes database. Finally, we performed a hierarchical clustering analysis on these genes using the Cluster 3.0 software program (http://bonsai.hgc.jp/ mdehoon/software/cluster) and visualized the clustered genes using Java Treeview (https://www.princeton.edu/ abarysh/treeview). Student's $t$-tests were used to determine statistical significance between the differentially expressed genes among the clusters. A $P$-value $<0.05$ was considered statistically significant.

\section{Cell culture}

NCI 60 cell lines, including all NSCLC cell lines, were obtained from the US National Cancer Institute (NCI; MTA no. 2702-09). Cells were incubated at $37^{\circ} \mathrm{C}$ and maintained at $5 \% \mathrm{CO}_{2} . \mathrm{H} 23, \mathrm{H} 226$, IMR-90 (normal lung fibroblasts, ATCC CCL-186) and lung primary (Primary Small Airway Epithelial Cells; Normal, Human, ATCC PCS-301-010) cell lines were obtained from American type culture collection (ATCC, Manassas, VA, USA). NSCLC cells were grown in RPMI 1640 medium (SH30027.01, HyClone, Logan, UT, USA) containing 10\% fetal bovine serum (SH30070.03HI, HyClone), penicillin and streptomycin. IMR-90 cells were grown in DMEM/HIGH GLUCOSE medium (SH30243.01, HyClone) containing 10\% FBS. Lung primary cells were grown in airway epithelial cell basal medium (PCS-300-030, ATCC) using a bronchial epithelial cell growth kit (PCS-300-040, ATCC). For ALDH overexpression, p3x FLAG-CMV-ALDH isoform constructs individually expressing $1 \mathrm{~A} 1,1 \mathrm{~A} 3,1 \mathrm{~B} 1,2,3 \mathrm{~A} 1,3 \mathrm{~A} 2,3 \mathrm{~B} 1$, 4A1, 5A1, 6A1, 7A1, 9A1, 1L1, 1L2 or 18A1 were produced by Cosmogenetech (Seoul, Korea). Each ALDH isoform complementary DNA sequence was obtained from the National Center for Biotechnology Information (NCBI). The ALDH plasmids were transfected into cells using Lipofectamine 3000 (Thermo Fisher Scientific Inc., Fremont, CA, USA) according to the manufacturer's instructions.

\section{Immunoblotting}

Cells were harvested and washed in phosphate-buffered saline (PBS) and then lysed in a buffer containing $20 \mathrm{~mm}$ Tris- $\mathrm{HCl}(\mathrm{pH} 7.4)$, $150 \mathrm{~mm} \mathrm{NaCl}, 1 \%$ (v/v) Triton X-100, $1 \mathrm{~mm}$ EDTA and protease inhibitors before undergoing an immunoblot analysis. The anti- $\beta$ actin antibody was purchased from Sigma-Aldrich (A5441, St Louis, MO, USA) and anti-ALDH1A3 (ab129815), anti-ALDH2 (ab54828), anti-ALDH3A2 (ab113111), anti-ALDH3B1 (ab93223) and antiALDH3B2 (ab96170) antibodies were purchased from Abcam (Cambridge, UK). Anti-ALDH3A1 (sc-137168), anti-cyclin B1 (sc-245) and anti- $\alpha$-tubulin (sc-23948) antibodies were purchased from Santa Cruz Biotechnology (Santa Cruz, CA, USA). The antipY15-Cdk1 antibody was purchased from Cell Signaling Technology (Dallas, TX, USA, \#9111S).

\section{Analysis of ALDH isozymes via multiple reaction- monitoring mass spectrometry}

Sample preparation. One primary lung and eight lung cancer cell lines (A549, EKVK, H322M, H23, H460, Hop62, Hop92 and IMR-90) were prepared. The harvested cells were resuspended in $400 \mu \mathrm{l}$ of chilled lysis buffer containing $8 \mathrm{M}$ urea, $50 \mathrm{~mm}$ Tris ( $\mathrm{pH} 8.0$ ), $64 \mathrm{~mm}$ sodium pyrophosphate, $1 \mathrm{~mm}$ sodium orthovanadate, $30 \mathrm{~mm} \mathrm{NaCl}$, $1 \times$ protease inhibitor cocktail and $1 \times$ phosphatase inhibitor cocktail. The cells were sonicated three times with 1-s pulses separated by $19 \mathrm{~s}$ of cooling at $4{ }^{\circ} \mathrm{C}$. The lysates were centrifuged at $13400 \mathrm{~g}$ for $10 \mathrm{~min}$ at $4{ }^{\circ} \mathrm{C}$ to remove cellular debris. Supernatants were collected, and the total protein amount was quantified using the BCA assay (Thermo, Waltham, MA, USA). The protein concentration was adjusted to $0.6 \mathrm{mg} \mathrm{ml}^{-1}$ using the lysis buffer.

Each cell lysate $(30 \mu \mathrm{g}$ in $50 \mu \mathrm{l})$ was mixed with $15 \mu \mathrm{l}$ of $50 \mathrm{~mm}$ Tris ( $\mathrm{pH} 8.0$ ) and $10 \mu \mathrm{l}$ of $50 \mathrm{~mm}$ tris-(2-carboxyethyl)-phosphine and then incubated at $25^{\circ} \mathrm{C}$ for $1 \mathrm{~h}$. To the reaction mixture, $20 \mu \mathrm{l}$ of $100 \mathrm{~mm}$ iodoacetamide was added, and mixtures were incubated for an additional $1 \mathrm{~h}$ in darkness. The samples were diluted fourfold with $50 \mathrm{~mm}$ Tris $(\mathrm{pH} \mathrm{8.0)}$ to reduce the urea concentration to less than $1 \mathrm{M}$. Proteins in the sample were digested with L-(tosylamido-2phenyl) ethyl chloromethyl ketone (TPCK)-treated trypsin (a 1:50 enzyme:substrate ratio; Promega, Madison, WI, USA) at $37^{\circ} \mathrm{C}$ for $16 \mathrm{~h}$. To stop the reaction, $25 \mu \mathrm{l}$ of $0.1 \%$ formic acid was added, and the sample was simultaneously spiked with $600 \mathrm{fmol}$ of tryptic digests of Escherichia coli $\beta$-galactosidase standard (AB SCIEX, Framingham, MA, USA). The digests were desalted with a C-18 spin column (Thermo), dried via vacuum centrifugation and stored at $-25^{\circ} \mathrm{C}$ until use.

Selection of ALDH isozyme peptide targets. We gathered the aminoacid sequences of $19 \mathrm{ALDH}$ isozymes from the Uniprot database (released as of 2014.02), digested the sequences in silico with trypsin and selected unique peptides for each ALDH isozyme. Peptides consisted of $6 \sim 20$ amino acids and had no missing cleavage sites. Detailed selection criteria are described in our previous paper. We considered at least five multiple reaction-monitoring (MRM) transitions of each peptide from spectral libraries such as GPMDB, PeptideAtlas and NIST. If a peptide was available, we used a fragmentation spectrum prediction program, PeptideArt. All candidate peptides were prescreened from six lung cell lines, namely, A549, H23, H322M, H460, IMB90 and Primary, via LC-MRM under the chosen MRM transition parameters. Among these candidates, 28 peptides representing $16 \mathrm{ALDH}$ isozymes were detected in this preliminary test (Table 2). If more than one peptide was detected for a single isozyme, the peptide showing the highest signal was chosen as a representative peptide and was used for quantitation of the corresponding ALDH isozyme in the study.

Liquid chromatography MRM mass spectrometry. Dried tryptic peptides were reconstituted with $30 \mu \mathrm{l}$ of $5 \%$ acetonitrile/ $0.1 \%$ formic acid, injected with a full-sample loop injection of $1 \mu \mathrm{l}$ and separated in a Nano cHiPLC ReproSil-Pur C18 column $(75 \mu \mathrm{m}$ inside diameter (i.d.) $\times 15 \mathrm{~cm}$ length, pore size $120 \AA$, particle size $3 \mu \mathrm{m}$; \#804-00011, Eksigent Technologies, Dublin, CA, USA) pre-equilibrated with 95\% Solvent A ( $0.1 \%$ formic acid in water) and 5\% Solvent B ( $0.1 \%$ formic acid in acetonitrile). Peptides were eluted at a flow rate of $300 \mathrm{nl} \mathrm{min}^{-1}$, with a gradient of $5-10 \%$ Solvent B for $4 \mathrm{~min}$, $10-25 \%$ for $30 \mathrm{~min}$ and $25-60 \%$ for $3 \mathrm{~min}$, followed by a $3-\mathrm{min}$ isocratic elution with $60 \%$ Solvent B. MRM measurements were performed using a QTrap5500 equipped with a nanoelectrospray ion source (AB SCIEX). The mass spectrometry was operated in the positive mode with the following settings: ion spray voltage of $2100 \mathrm{~V}$, curtain gas at 20 p.s.i., nebulizer gas at 25 p.s.i., resolution at $0.7 \mathrm{Da}$ (unit resolution) for $\mathrm{Q} 1 / \mathrm{Q} 3$, interface temperature at $150^{\circ} \mathrm{C}$ and a scan mass range of $300-1250 \mathrm{~m} / \mathrm{z}$. The declustering potential (DP) and collision energy (CE) values were set based on the Skyline (version 2.5) default value. A scheduled MRM mode with detection windows of $300 \mathrm{~s}$ and a cycle time of $1.5 \mathrm{~s}$ was used. Each sample was analyzed three times with three technical replicates. 
Quantification of MRM measurements. Skyline was used to quantify MRM measurements by calculating the peak areas of extracted ion chromatograms. To determine whether a peptide was detected in each cell line, we applied highly stringent criteria: (i) raw peak area greater than 5000, (ii) signal to noise ratio higher than 3 and (iii) coefficient of variation lower than $25 \%$ for the technical triplicates. The raw peak area values were normalized as described below.

Two types of standards were used for normalization. Two peptides from human glyceraldehyde-3-phosphate dehydrogenase (Swiss-Prot accession: P04406), GALQNIIPASTGAAK and LISWYDNEFGYSNR, were used as endogenous internal standards and two peptides of E. coli $\beta$-galactosidase, IDPNAWVER and GDFQFNISR, were used as external spiked standards. Normalized peak areas of target ALDH isoforms were calculated as follows:

$$
\breve{P}_{i, s}=P_{i, s} \times \sqrt{\sqrt{\prod_{j=1}^{2} \frac{\hat{n}_{j}}{n_{j, s}}} \times \sqrt{\prod_{k=1}^{2} \frac{\hat{x}_{k}}{x_{k, s}}}}
$$

where $\breve{P}_{i, s}$ and $\mathrm{P}_{i, s}$ are the normalized and raw peak areas, respectively, of the $i$-th peptide in sample $s, \hat{n}_{j}$ is the maximum peak area of the $j$-th endogenous standard peptide over all samples in the study, $n_{j, s}$ is the raw peak area of the $j$-th endogenous standard peptide in sample $s, \hat{x}_{k}$ is the maximum peak area of the $k$-th exogenous spiked standard peptide over all samples and $x_{k, s}$ is the raw peak area of the $k$-th exogenous spiked standard peptide in sample $s$ (Table 3). All statistical data were analyzed using the R software (version 2.8.1) and Excel 2010 (version 14.0, Microsoft Office, Redmond, WA, USA).

\section{Measurement of ATP and NADH/NAD ${ }^{+}$levels}

Total ATP levels were monitored using a CellTiter-Glo Luminescent Cell Viability Assay as per the manufacturer's instructions (G7572, Promega, Durham, NC, USA). CellTiter-Glo was added to $1 \times 10^{6}$ cells, which were then placed on an orbital shaker to induce cell lysis. The samples were then read on a chemiluminescence plate reader (VICTOR light 1420; integration time of $1 \mathrm{~s}$ ). Total NADH and $\mathrm{NAD}$ levels were measured using the NAD/NADH Quantitation Colorimetric Kit (K337-100, BioVision, Milpitas, CA, USA). To obtain total NAD (NADH and NAD), NADH/NAD Extraction Buffer was added to $2 \times 10^{5}$ cells, and a portion of the NADH/NAD extract was heated for $30 \mathrm{~min}$ at $60^{\circ} \mathrm{C}$ to decompose the NAD. The NADH and $\mathrm{NAD}$ extracts were converted to $\mathrm{NADH}$ using the NADH-cycling enzyme, and samples were then read on an ELISA reader (Power wave HT, Biotek, Winooski, VT, USA).

\section{FITC Annexin V apoptosis detection}

NSCLC cells were treated as indicated for $48 \mathrm{~h}$, washed twice in cold PBS, centrifuged at 1400 r.p.m. for 3 min and resuspended in binding buffer at a concentration of $1 \times 10^{6}$ cells per ml. Portions $(100 \mu \mathrm{l})$ of the solutions were then transferred to 5 -ml culture tubes $\left(1 \times 10^{5}\right.$ cells $)$ before the addition of $5 \mu \mathrm{l}$ each of annexin $\mathrm{V}$-fluorescein isothiocyanate (FITC) and propidium iodide. Cells were gently vortexed and incubated for $15 \mathrm{~min}$ at room temperature (RT) in the dark. Binding buffer $(400 \mu \mathrm{l})$ was added to each sample before analysis via flow cytometry (BD Biosciences, San Jose, CA, USA).

\section{DNA FACS analysis}

A549 and EKVX cells were trypsinized and fixed in 70\% (vol/vol) ethanol for DNA staining. For the cell cycle analysis, fixed cells were washed with PBS, and subsequently resuspended in a propidium iodide / RNase staining solution $\left(0.05 \mathrm{mg} \mathrm{ml}^{-1}\right.$ propidium iodide and
$0.1 \mathrm{mg} \mathrm{ml}^{-1}$ RNase A in PBS). Fluorescence-activated cell sorting (FACS) analyses were performed by using a FACSCanto II system (BD Biosciences).

\section{Mitotic index}

Condensed chromosomes in mitotic cells were intensively visualized by staining them with an aceto-orcein solution (Merck, Billerica, MA, USA) under a light microscope. Mitotic indices were determined based on the percentage of mitotic cells with condensed chromosomes.

\section{Cell cycle synchronization and drug treatment}

For the analysis of the G1/S transition, A549 and EKVX cells were blocked at the G1/S boundary by treating them with 2 mм thymidine for 12 or $22 \mathrm{~h}$, respectively, and the cells were treated with gossypol and/or phenformin $6 \mathrm{~h}$ before thymidine release. Then, synchronized cells were released into the $\mathrm{S}$ phase by washing them three times with PBS. Released cells were incubated again with fresh media plus the same drug(s) they were previously treated with. For the analysis of the G2/M transition, A549 and EKVX cells were blocked at the G1/S boundary by treating them with $2 \mathrm{~mm}$ thymidine for 12 or $22 \mathrm{~h}$, respectively, and then releasing them into the $S$ phase by washing the cells three times with PBS and subsequently incubating them with fresh media plus gossypol and/or phenformin.

\section{Flow cytometry}

Cells were collected into single-cell suspensions using trypsin/EDTA, fixed with $4 \%$ formaldehyde and then permeabilized with $0.1 \%$ Triton $\mathrm{X}-100$. Cells were stained with an anti-ALDH1A3 polyclonal antibody and a phycoerythrin-conjugated anti-rabbit antibody (Biotium, Hayward, CA, USA). Flow cytometric analyses were performed at the Flow Cytometry Core (National Cancer Center) using a FACSVerse flow cytometer (BD Biosciences).

\section{Aldefluor activity assay}

To measure Aldefluor activity, we used an ALDEFLUOR kit (StemCell Technologies, Vancouver, BC, Canada) according to the manufacturer's instructions. Briefly, cells were suspended in Aldefluor assay buffer containing an ALDH substrate (BODIPY-aminoacetaldehydediethyl acetate, BAAA-DA) and incubated at $37^{\circ} \mathrm{C}$ for $45 \mathrm{~min}$. As a negative control for each sample of cells, an aliquot of the sample was treated with diethylaminobenzaldehyde, a specific ALDH inhibitor. The cells were detected in the FL-1 channel of a flow cytometer (BD Biosciences).

\section{Immunohistochemical staining and evaluation}

Tissue arrays (CC5, various human lung cancer tissues; CCN5, normal human lung tissues) were purchased from SuperBioChip (Seoul, Korea). Immunohistochemical staining was performed using an UltravisionLP Detection System (Thermo Fisher Scientific Inc., Fremont, CA, USA) and the results are shown in Figure 1. Briefly, after deparaffinization of formalin-fixed, paraffin-embedded human NSCLC tissues, antigens were retrieved in $10 \mathrm{~mm}$ citrate buffer $(\mathrm{pH}$ 6.0 ) containing $0.05 \%$ Tween- 20 . The tissues were sequentially treated with $3 \%$ hydrogen peroxide and Ultra V blocking solution. After a 1-h incubation at RT with primary antibodies, the slides were washed in Tris-buffered saline with Tween-20 (TBST), incubated with a primary antibody enhancer for $10 \mathrm{~min}$ and exposed to horseradish peroxidaseconjugated secondary antibodies for $15 \mathrm{~min}$. After re-washing in TBST, the tissue slides were incubated with the chromogen 
a

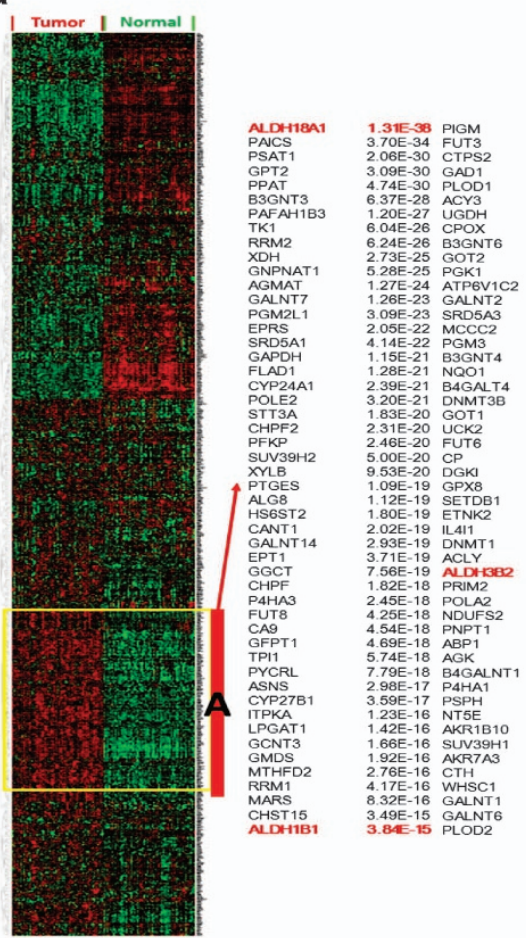

b


d

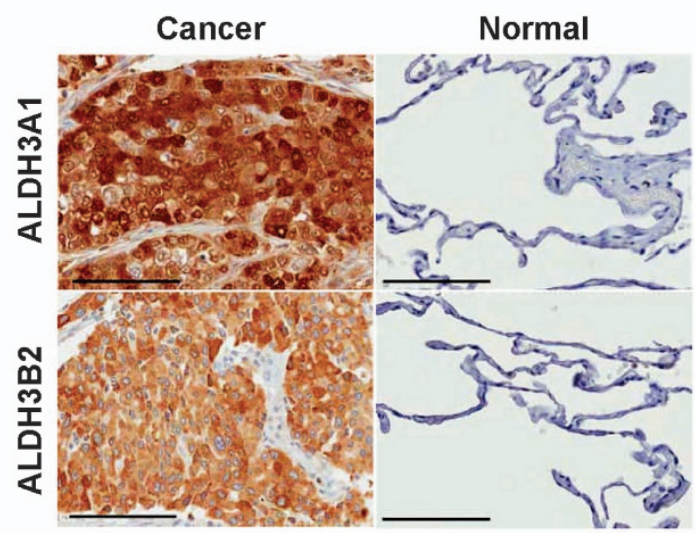

e

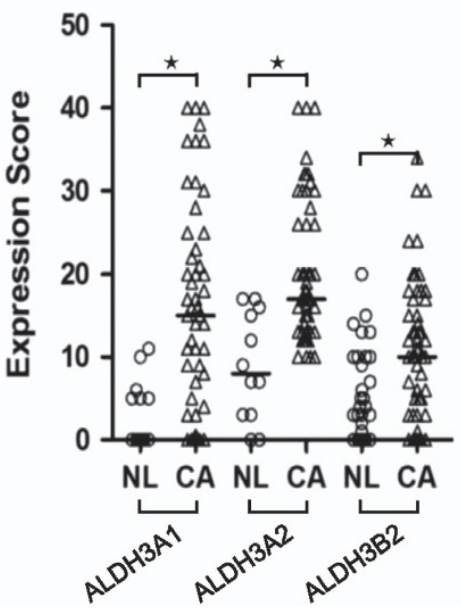

Figure 1 High aldehyde dehydrogenase (ALDH) isoform expression levels are associated with poor overall survival in non-small-cell lung cancer (NSCLC). (a) Metabolic gene clustering of samples from lung adenocarcinoma patients from The Cancer Genome Atlas (TCGA). The clustered genes in set $\mathrm{A}$ were upregulated in the tumor group, and 150 metabolic genes with $P<0.05$ are listed. (b) Clustering analysis of six ALDH isoforms. Data for ALDH18A1 $\left(P=1.31 \times 10^{-38}\right)$, ALDH1B1 $\left(P=3.84 \times 10^{-15}\right)$, ALDH3B2 $\left(P=1.17 \times 10^{-10}\right)$, ALDH1L2 $\left(P=1.58 \times 10^{-05}\right)$, ALDH7A1 $\left(P=1.09 \times 10^{-4}\right)$ and ALDH1L1 $\left(P=2.32 \times 10^{-2}\right)$ are shown. Gene expression values were normalized using standard normalization (mean $=0$ and s.d. $=1$ ). Each row of the heat map is sorted in an ascending order according to the $P$-value. (c) Relative Aldefluor activity from various NSCLC cell lines and primary human lung cells. ${ }^{* *} P<0.01, * * * P<0.001$. (d) Immunohistochemical staining of ALDH isoforms in normal and cancerous lung tissue. Scale bar $=100 \mu \mathrm{m}$. (e) Expression of ALDH3A1, ALDH3A2 and ALDH3B2 in cancerous (CA, triangles) and normal lung type I and II pneumocytes (NL, circles). ${ }^{*} P<0.001, n=59$ for each sample. 
diaminobenzidine (Scytek Laboratories Inc., Logan, UT, USA) and counterstained with Mayer's hematoxylin (Dako Cytomation, Glostrup, Denmark). To evaluate cytoplasmic staining for ALDH isoforms, staining intensity was scored on a scale of $0-3$ as follows: 0 , no staining of cancer cells; 1 , weak staining; 2 , moderate staining; 3 , strong staining. In addition, the percentage of positive cells among the cancer cells was scored. These two scores were multiplied, and the resulting value was used as the expression score.

\section{Statistical analysis}

Statistical analysis was performed using Student's $t$-tests as appropriate.

\section{RESULTS}

ALDH isoforms are highly expressed in LUAD

A bioinformatics analysis was performed to assess the expression profiles of metabolic enzymes in NSCLC patients and to identify a distinguishable metabolic context upon which cancer cells depend for survival. The heat map generated from this analysis consists of $\sim 1,600$ metabolic genes in 57 pairs of sequencing data selected from 488 LUAD patients (Figure 1a). Our robust clustering analysis and test of statistical significance from the RNA sequencing data for LUADs from The Cancer Genome Atlas revealed several ALDH isoforms that were upregulated in LUAD patients (Figure 1b). The clustering of samples from LUAD patients consistently segregated them into tumor and normal groups (Table 1). ALDH activity in the NSCLC cell lines was measured using an Aldefluor activity kit and was found to be increased in most cell lines compared with activity in control IMR-90 fibroblasts (Figure 1c). To test whether increased expression of ALDH isoforms is also observed in NSCLC cases, immunohistochemical staining was performed for two ALDH subtypes, ALDH3A1 and ALDH3B2.

Table 1 Summary of $P$-values from expression profiling of ALDH isoforms in LUAD patients

\begin{tabular}{ll}
\hline Gene name & LUAD (11) \\
\hline ALDH1A1 & $1.079 \mathrm{E}-13$ \\
ALDH1A2 & $3.467 \mathrm{E}-13$ \\
ALDH1A3 & 0.62022 \\
ALDH1B1 & $3.84 \mathrm{E}-15$ \\
ALDH1L1 & 0.023232 \\
ALDH1L2 & $1.58 \mathrm{E}-05$ \\
ALDH2 & $6.72 \mathrm{E}-17$ \\
ALDH3A1 & 0.18286 \\
ALDH3A2 & $7.952 \mathrm{E}-05$ \\
ALDH3B1 & $2.201 \mathrm{E}-10$ \\
ALDH3B2 & $1.17 \mathrm{E}-10$ \\
ALDH4A1 & 0.59241 \\
ALDH5A1 & 0.16429 \\
ALDH6A1 & 0.7336 \\
ALDH7A1 & 0.000109 \\
ALDH9A1 & 0.17913 \\
ALDH18A1 & $1.31 \mathrm{E}-38$ \\
\hline
\end{tabular}

Abbreviations: ALDH, aldehyde dehydrogenase; LUAD, lung adenocarcinoma.
Other cellular components of normal lung tissue, including type I and II pneumocytes, showed little to no ALDH expression. Lung cancer tissues, however, displayed much higher ALDH levels (Figures 1d and e). Taken together, these data indicate that levels of ALDH isoforms are increased in lung cancer.

To examine their differential expression in NSCLC cells, the expression levels of 16 ALDH isoforms in nine lung cancer cell lines were measured via liquid chromatography MRM mass spectrometry (Figure 2a). To compare the expression levels of each ALDH isoform in the different cell lines, MRM peak areas were normalized against the largest nine values (Figure 2b, Tables 2 and 3). Immunoblotting confirmed the differential expression of these ALDH isoforms (Figure 2c). Flow cytometric analysis of ALDH1A3 showed that this protein is expressed ubiquitously rather than only in a specific cell population, suggesting that ALDH isoforms are widely expressed in NSCLC cells (Figure 2d).

\section{Treatment with gossypol significantly decreases ATP production in NSCLC cells}

A total of 15 ALDH isozymes were cloned and expressed in EKVX cells. Our results demonstrate that the transfection of ALDH isozymes generally increases ATP levels by over $10 \%$ (Figure 3a). Transfection of ALDH1L1, ALDH1L2, ALDH2, ALDH3A1, ALDH3A2, ALDH3B1 and ALDH18A1 resulted in increases of ATP of over $20 \%$. In particular, ALDH1L1 gene transfection was associated with a $30 \%$ increase in ATP production (Figure 3a). Treating each ALDH gene transfectant with $10 \mu \mathrm{M}$ gossypol, a pan-ALDH inhibitor, reduced ATP production to $\sim 60-70 \%$ that of the control, suggesting that gossypol can inhibit most ALDH isoforms in NSCLC cells. Taken together, these data suggest that ALDH has a crucial role in $\mathrm{NADH}$ production in the cytoplasm, which is required for ATP production. The effect of gossypol treatment on ATP production in NSCLC cells was compared with its effect on primary lung epithelial cells (Figure 3b). Treating NSCLC cell lines with $10-\mu \mathrm{M}$ gossypol inhibited ATP production by 25-50\% (Figure 3b). Although normal primary lung epithelial cells showed decreases in ATP production of 28\%, the ATP levels in normal cells were four to sevenfold lower than the levels in cancer cells (Figure 3b).

\section{Gossypol induces cell cycle arrest through ATP depletion in NSCLC}

Some reports have shown that decreases in ATP levels can induce cell cycle arrest at the G1/S transition as well as at the G2/M transition. ${ }^{6,7}$ To test whether a dual treatment with gossypol and phenformin could be used to regulate the cell cycle, we performed a cell cycle analysis with or without drug treatments. An analysis of cell cycle progression using thymidine block-induced synchronized cells clearly revealed cell cycle progression delay at the G2/M transition (Figure 4a), which agrees with previous reports on the presence of ATP-dependent cell cycle checkpoints at the G2/M transition., ${ }^{6,7}$ Moreover, a delay in mitotic progression was even more 


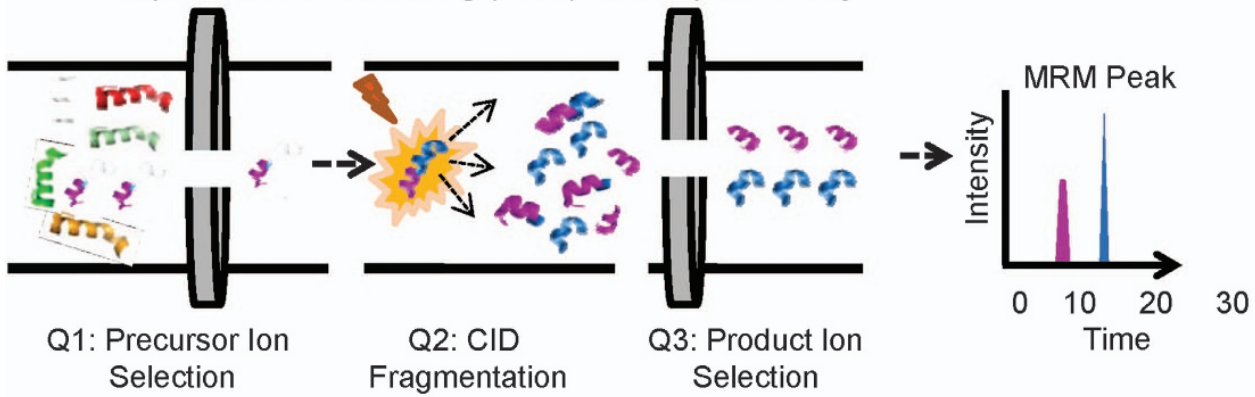

b

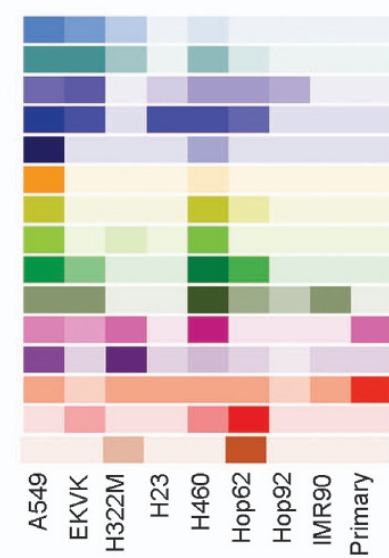

ALDH7A1 ALDH3B1

ALDH4A1

ALDH5A1

ALDH1B1

ALDH1A1

ALDH2

ALDH3A1

ALDH1L2

ALDH16A1

ALDH9A1

ALDH3A1

ALDH18A1

ALDH6A1

ALDH1A3



c

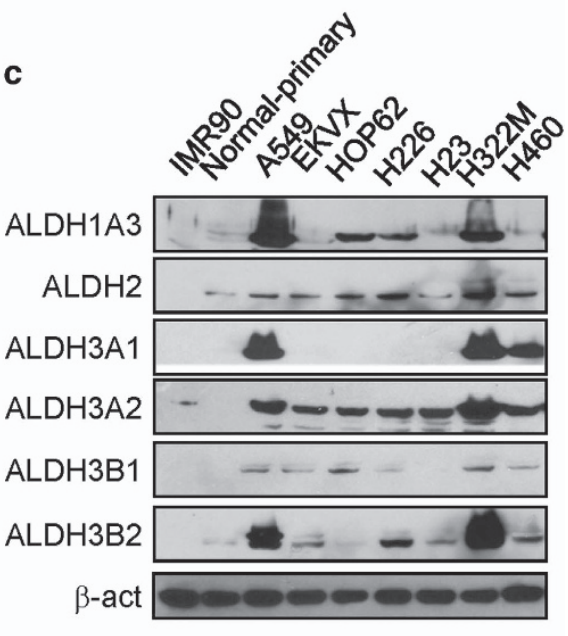

d
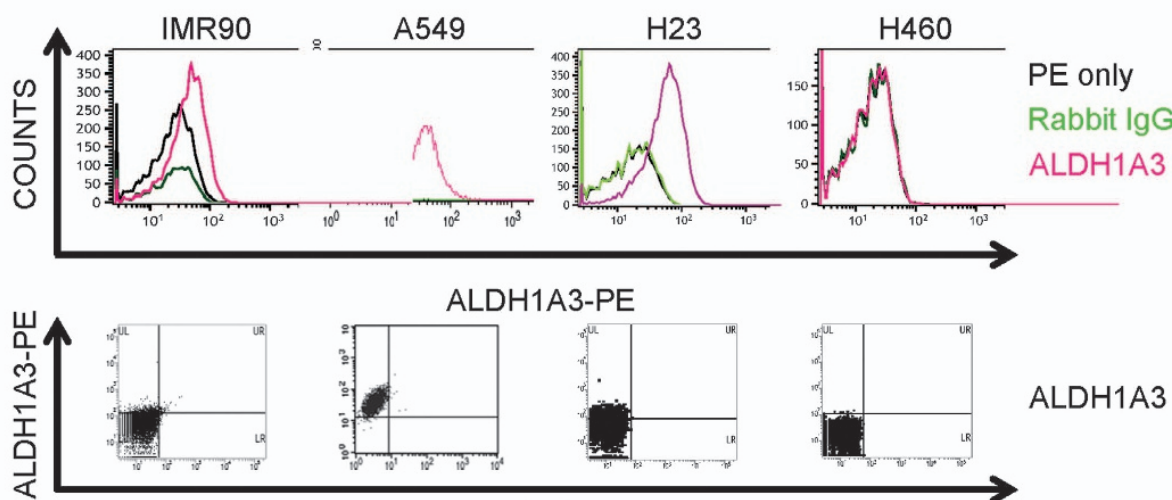

ALDH1A3-PE
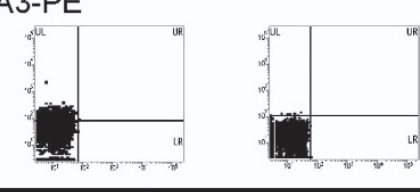

ALDH1A3

\section{FITC}

Figure 2 Multiple isoforms of aldehyde dehydrogenase (ALDH) show increased expression in non-small-cell lung cancer (NSCLC) cells. (a) Schematic diagram of liquid chromatography multiple reaction-monitoring mass spectrometry (LC-MRM-MS). (b) Expression of ALDH isoforms in lung cancer cell lines was measured via MRM-MS. (c) Immunoblot analysis of ALDH isoforms in NSCLC cell lines. IMR-90 and normal lung airway cells were used as non-cancer controls, whereas $\beta$-actin was used as a loading control. (d) ALDH1A3 was ubiquitously expressed in NSCLC cells as determined via flow cytometric analysis.

significant in the case of the combined treatment (Figure $4 \mathrm{a}$ ). The inhibition of the G2/M transition seemed to induce significant decreases in mitotic indices in asynchronous cultures of both cell lines (Figure 4b). Further analysis of the cycle of synchronized cells revealed a delay in the cell cycle progression at the G1/S transition in A549 cells as well (Figure 4c), agreeing with previous reports on the presence of ATP-dependent cell cycle checkpoints at the G1/S transition. ${ }^{6,7}$ To test whether the observed cell cycle arrest is due to cell death, cell death was analyzed in A549 and EKVX cells via FACS at the point of cell cycle arrest (Figure 4d). However, cell death was not detected at the time of cell cycle arrest. This suggests that prolonged cell cycle arrest may stress the cancer cells, eventually inducing apoptosis.

The combination treatment of gossypol and phenformin for $48 \mathrm{~h}$ increased cell death by 4.75 -fold in EKVX cells compared with cell death in the control treatment, whereas treatment with only gossypol increased cell death by 2.58 -fold in EKVX cells compared with cell death in the control treatment (Figure 5a). Moreover, ATP production was decreased by 


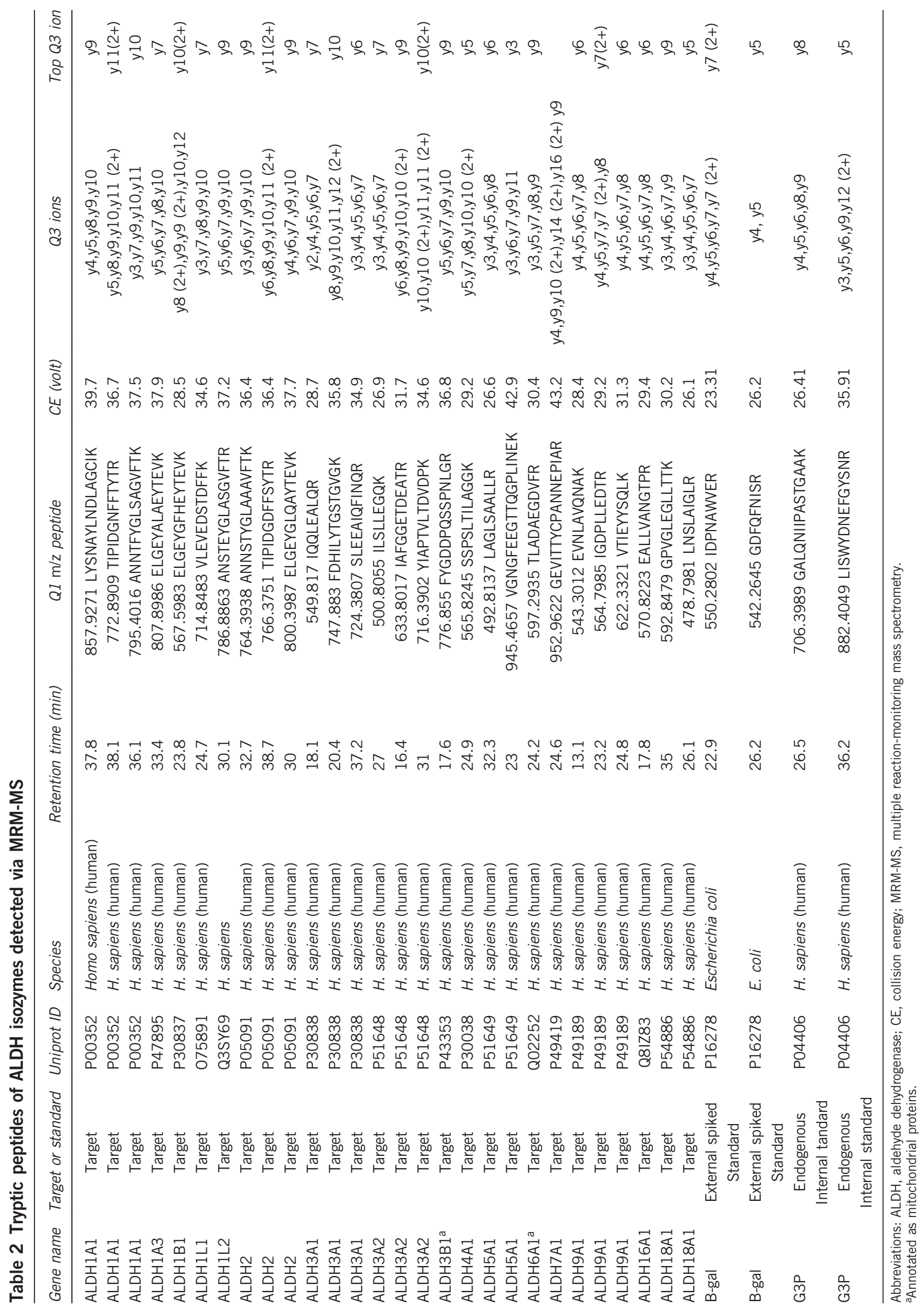




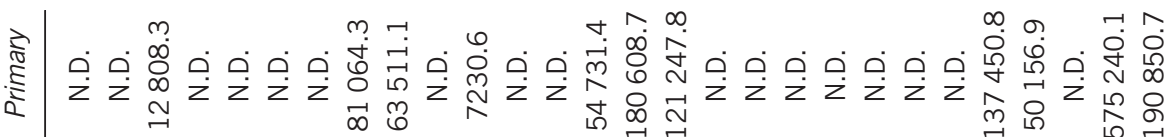

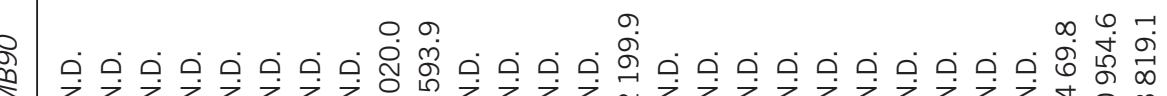

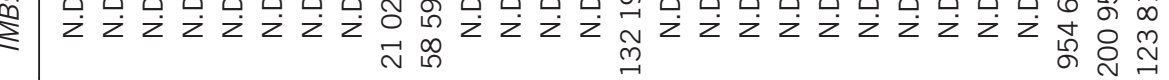

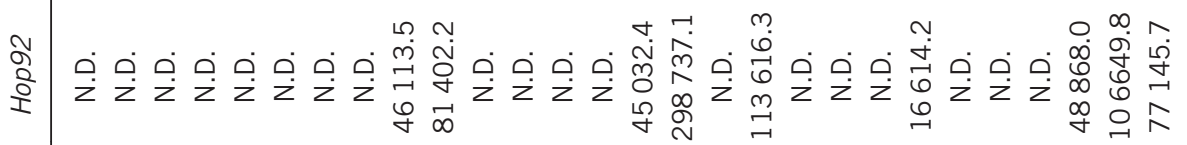

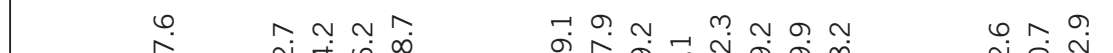

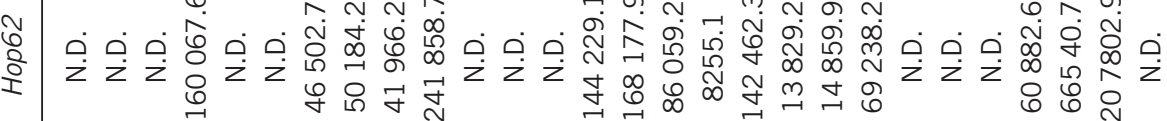
-

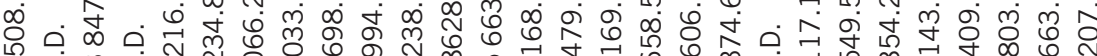

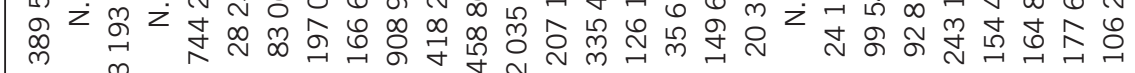






我

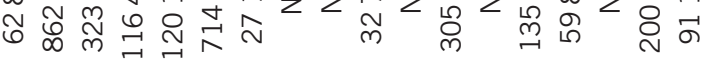

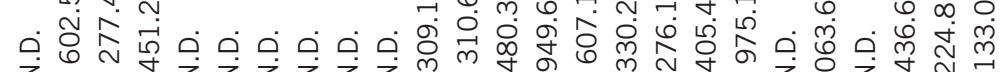

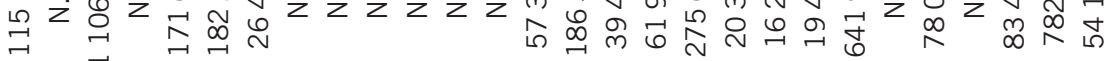

ก

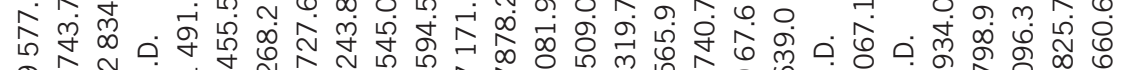

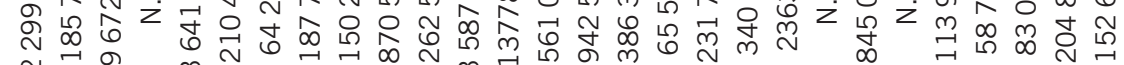

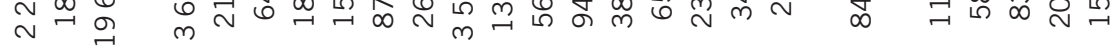
空 

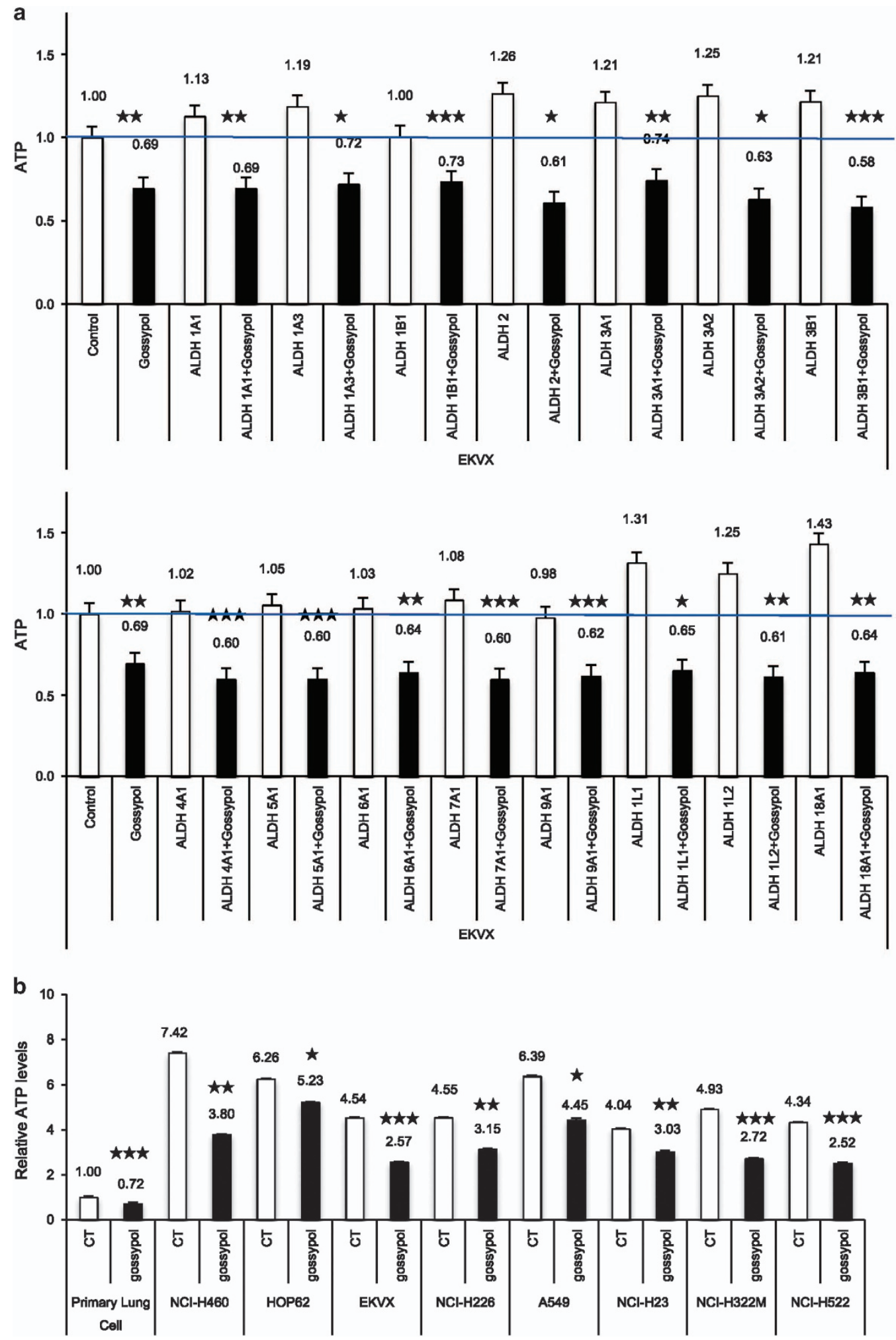

Figure 3 Treatment with the aldehyde dehydrogenase (ALDH) inhibitor gossypol induces ATP depletion. (a) Effect of $10 \mu \mathrm{m}$ of gossypol on ATP production in EKVX cells overexpressing various ALDH isoforms. Overexpression primer sets of ALDH isoforms are summarized in the Table 4. (b) Differences in the effect of $10 \mu \mathrm{m}$ of gossypol on ATP production between non-small-cell lung cancer (NSCLC) cell lines and primary lung epithelial cells were tested. ${ }^{*} P<0.05,{ }^{*} P<0.01,{ }^{* * *} P<0.001$ compared with control. 

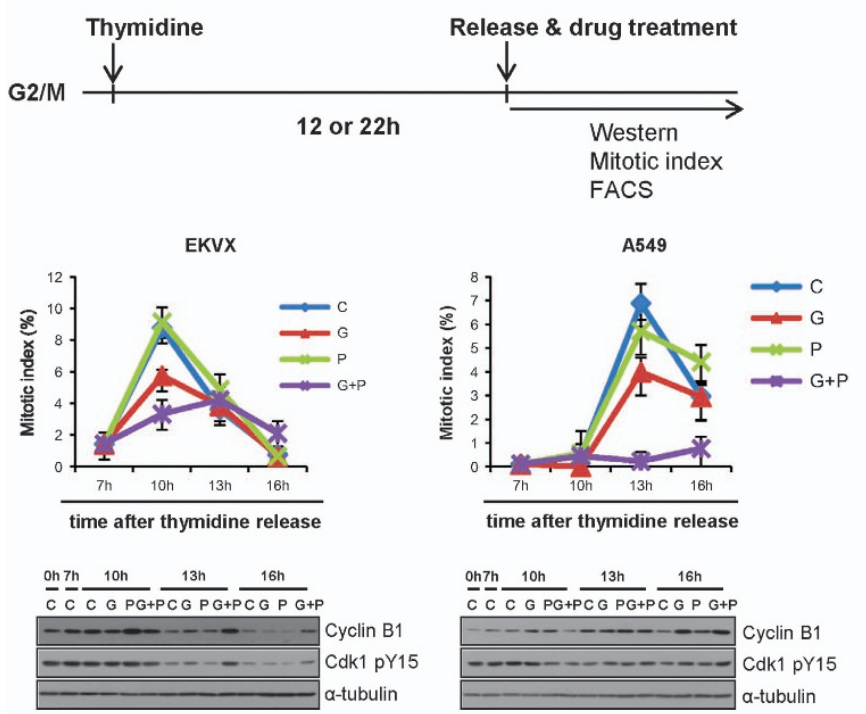

Oh7h 10h $13 \mathrm{~h} \quad 16 \mathrm{~h}$ C C C GPG $+P C G P G+P C G P G+P$ - Cyclin B1 - Cdk1 pY15 - - a-tubulin

b

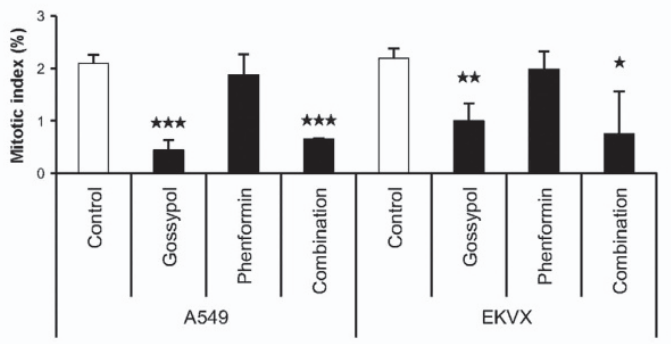

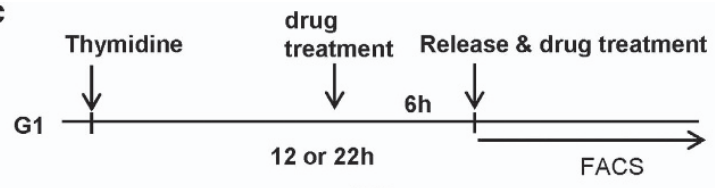
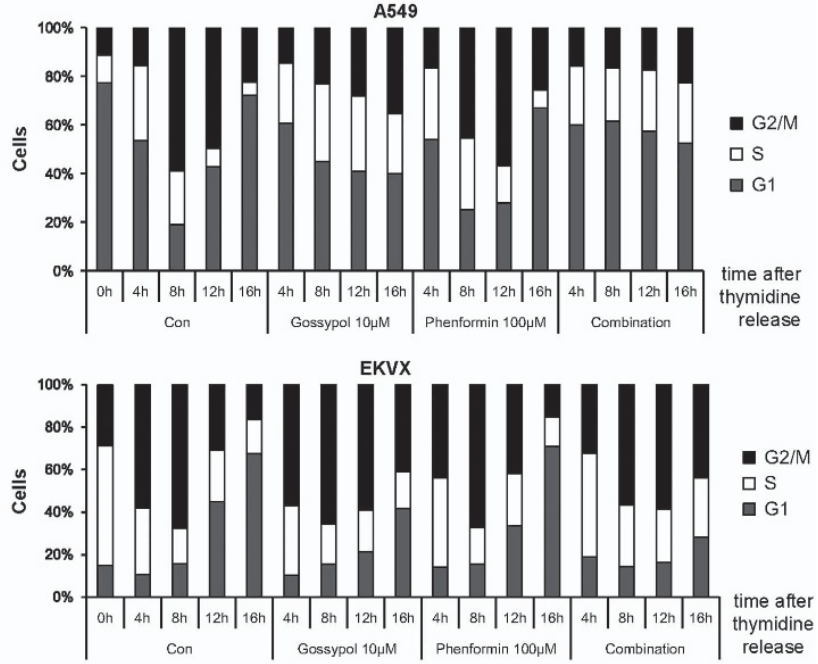

d
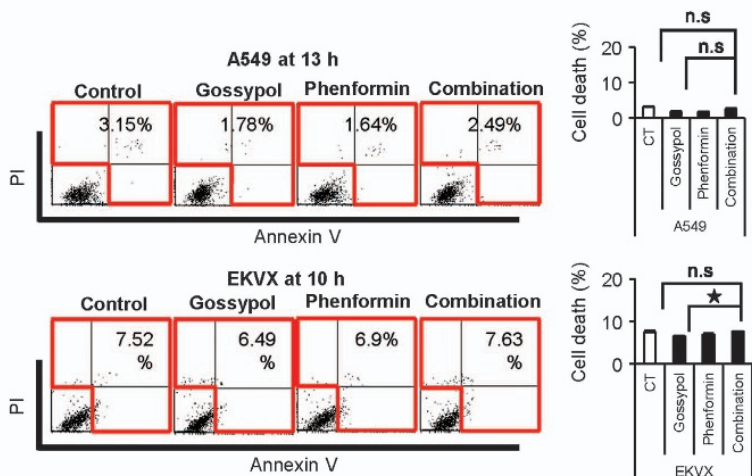

Figure 4 Gossypol combined with phenformin enhances cell cycle arrest and induces cell death in non-small-cell lung cancer (NSCLC). (a) G2/M transition of synchronized cells (following the protocol of a single thymidine block as shown in the upper panel) was monitored via mitotic index assessment (middle panel) and western blot analysis (lower panel) in the presence or absence of the indicated chemicals. Cyclin B1 is a marker for mitotic exit. pY15 of Cdk1 is a marker for the G2/M transition. (b) Effect of gossypol (10 $\mu \mathrm{m}$ ), phenformin $(100 \mu \mathrm{M})$ or a combined treatment for $24 \mathrm{~h}$ on the mitotic index of asynchronous cells. ${ }^{*} P<0.05,{ }^{* *} P<0.01,{ }^{* * *} P<0.001$ compared with vehicle control. (c) G1/S transition of synchronized cells (following the protocol of a single thymidine block as shown in the upper panel) was monitored via DNA FACS analysis (lower panel) in the presence or absence of the indicated chemicals. Note that EKVX cells were mainly arrested at the early S phase, whereas A549 cells were mainly arrested at the G1 phase. (d) To measure cell death, A549 and EKVX cells were treated with gossypol $(10 \mu \mathrm{m})$, phenformin $(100 \mu \mathrm{m})$, combination for 13 and $10 \mathrm{~h}$, respectively. Cell death was measured by flow cytometric analysis. Data are representative of the mean and s.d. of three independent experiments. ${ }^{\star} P<0.05$ compared with control.

$81 \%$ in EKVX cells. We also tested whether gossypol reduced the levels of B-cell lymphocyte/leukemia-2 (Bcl-2) during the induction of cell death and found that the treatment resulted in no change in Bcl-2 levels (Figure 5b).

\section{DISCUSSION}

This study revealed that gossypol combined with phenformin significantly increases the therapeutic response of NSCLC. Here, we found that gossypol induces cell cycle arrest via ATP depletion, which can produce greater anticancer effects when combined with phenformin treatment.
ALDH expression has been recognized as a drug resistance marker in cancer (see reviews in Januchowski et al. ${ }^{8}$ ). By exploring the role of ALDH, previous studies have found that the expression of ALDH isoforms such as ALDH1 and ALDH3A1 are highly upregulated in cancer stem cells. ${ }^{9}$ A proposed role of ALDH in cancer stem cells is the conversion of activated cyclophosphamide to the inactive excretory product carboxyphosphamide. ${ }^{10}$ Here, we found that ALDH isoforms are expressed in every cell of cancer cell lines, which conflicts with cancer stem cell theory. However, a previous report agrees with our observation that ALDH1 is not a suitable 
a

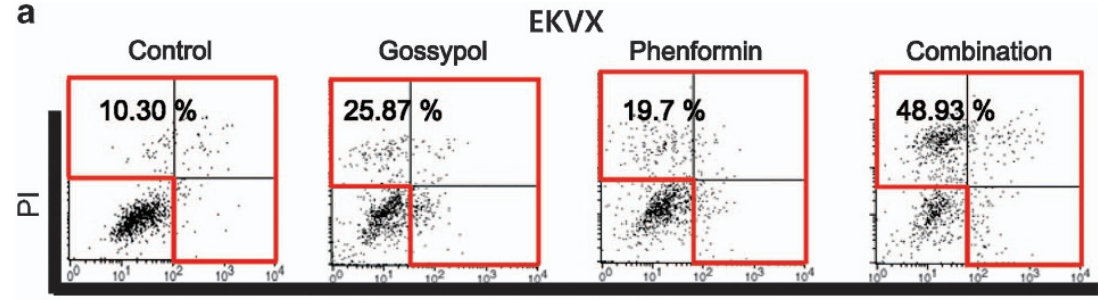

Annexin V
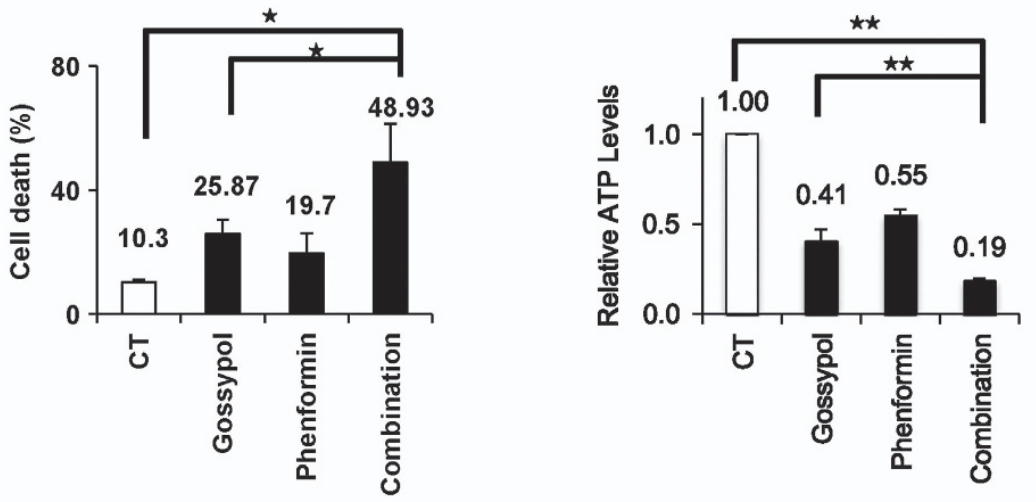

b

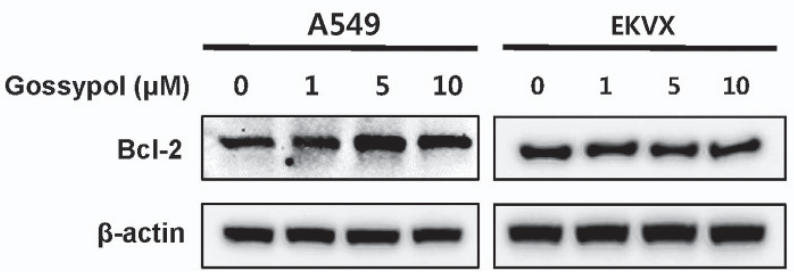

Figure 5 Gossypol combined with phenformin induces cell death in non-small-cell lung cancer (NSCLC) associated with ATP depletion. (a) Effect of gossypol $(10 \mu \mathrm{m})$, phenformin $(100 \mu \mathrm{m})$ or a combined treatment for $48 \mathrm{~h}$ on cell death as determined via flow cytometric analysis and ATP production determined via ATP assay. (b) Effect of gossypol (10 $\mu \mathrm{m})$, phenformin (100 $\mu \mathrm{m})$ or a combined treatment on Bcl-2 expression in NSCLC cells was determined via immunoblotting. Data are representative of the mean and s.d. of three independent experiments. ${ }^{*} P<0.05,{ }^{* *} P<0.01$ compared with control.

CSC marker because its expression is also detected in epithelial cancer cell lines. ${ }^{11}$ Therefore, there is no clear evidence for the role of ALDH in cancer, although ALDH inhibitors increase the effect of chemotherapy. ${ }^{12}$ This study revealed that NSCLC is highly dependent on ALDH for ATP production because ALDH produces NADH, which acts as an electron carrier for ATP synthesis.

Gossypol is a terpenoid extracted from cottonseeds that has been used as an antispermatogenic agent in Chinese medicine. Gossypol is known as a non-competitive inhibitor of substrate binding in ALDH-induced oxidation and a strong competitive inhibitor against cofactors such as $\mathrm{NAD}^{+} .{ }^{13,14}$ In vitro kinetic studies have shown that gossypol exerts greater effects on the ALDH3 isozyme than on the ALDH1 and ALDH2 isozymes ${ }^{15}$ (see reviews in Kopakka et al. ${ }^{14}$ ). Gossypol has also been identified to competitively bind to Bcl-2 homology (BH) domains in Bcl-2 family, which blocks the $\mathrm{BH} 3$ dimerization domain of pro-apoptotic proteins binding to $\mathrm{Bcl}_{-} \mathrm{XL}^{16}$ In line with this theory of $\mathrm{Bcl}-2$ inhibition, gossypol treatment has been shown to decrease $\mathrm{Bcl}-2$ protein levels. ${ }^{17,18}$ However, in this study, we did not observe any change of $\mathrm{Bcl}-2$ protein levels (Figure 5b). Whatever the mechanism, single or combined treatments with gossypol have been associated with limited anticancer efficacy in clinical trials. Treatment with gossypol alone (40 mg per day) during a phase I/II clinical study of metastatic breast cancer refractory to doxorubicin and paclitaxel also demonstrated a limited therapeutic response. ${ }^{19}$ Recently, a randomized study combining AT-101 (R-(-)gossypol acetic acid) with docetaxel in patients with advanced NSCLC showed negligible survival advantages as a second-line treatment. ${ }^{20}$ This suggests that there is a limit to the use of gossypol as a single therapeutic option in treating cancer.

The Warburg effect in cancer proposes that glucose is the primary source of carbon for biomolecule synthesis ${ }^{21}$ even though glycolysis contributes to ATP synthesis.

In this study, we found that ALDH contributes to ATP production through the supply of NADH in NSCLC. This suggests that NSCLC depends on cytosolic NADH for ATP production in the mitochondria. However, the mechanisms involved in $\mathrm{NADH}$ transportation via the malate-aspartate shuttle remain to be verified in NSCLC.

Phenformin is known to block electron transfer at mitochondrial complex I, which results in the inhibition of ATP synthesis. The combined treatment with gossypol and 
Table 4 Expression constructs of ALDH isoforms used in this study

Insert

\begin{tabular}{|c|c|c|c|c|c|c|}
\hline No & Vector & Gene template & \multicolumn{2}{|r|}{ Primer sequences } & \multirow{2}{*}{$\frac{\text { Enzyme site }}{\text { HindIII }}$} & \multirow{2}{*}{$\frac{\text { Amplicon size (bp) }}{1506}$} \\
\hline \multirow[t]{2}{*}{1} & p3XFlag-CMV & ALDH1A1 & $\mathrm{F}^{\prime}$ & TGACGATGACAAGCTTATGTCATCCTCAGGCACG & & \\
\hline & & & $\mathrm{R}^{\prime}$ & TCGCGGCCGCAAGCTT TTATGAGTTCTTCTGAGAG & HindIII & \\
\hline 2 & & & $\mathrm{R}^{\prime}$ & TCGCGGCCGCAAGCTT TCAGGGGTTCTTGTCGCC & HindIII & \\
\hline 3 & p3XFlag-CMV & ALDH1B1 & $\mathrm{F}^{\prime}$ & TGACGATGACAAGCTT ATGCTGCGCTTCCTGGCAC & HindIII & 1554 \\
\hline & & & $\mathrm{R}^{\prime}$ & TCGCGGCCGCAAGCTT TTATGAGTTCTTCTGAGGC & HindIII & \\
\hline \multirow[t]{2}{*}{5} & p3XFlag-CMV & ALDH3A1 & $\mathrm{F}^{\prime}$ & TGACGATGACAAGCTT ATGAGCAAGATCAGCGAG & HindIII & 1362 \\
\hline & & & $\mathrm{R}^{\prime}$ & TCGCGGCCGCAAGCTT TCAGTGCTGGGTCATCTTG & HindIII & \\
\hline \multirow[t]{2}{*}{6} & p3XFlag-CMV & ALDH3A2 & $F^{\prime}$ & TGACGATGACAAGCTT ATGGAGCTCGAAGTCCGGC & HindIII & 1527 \\
\hline & & & $\mathrm{R}^{\prime}$ & TCGCGGCCGCAAGCTT TCATCTCTGCTTACTGGAC & HindIII & \\
\hline \multirow[t]{2}{*}{9} & p3XFlag-CMV & ALDH5A1 & $\mathrm{F}^{\prime}$ & TGACGATGACAAGCTT ATGGCGACCTGCATTTGGC & HindIII & 1647 \\
\hline & & & $\mathrm{R}^{\prime}$ & TCGCGGCCGCAAGCTT CTACAAGCCCCCGTAACAC & HindIII & \\
\hline \multirow[t]{2}{*}{10} & p3XFlag-CMV & ALDH6A1 & $\mathrm{F}^{\prime}$ & TGACGATGACAAGCTT ATGGCGGCGCTATTGGCG & HindIII & 1608 \\
\hline & & & $\mathrm{R}^{\prime}$ & TCGCGGCCGCAAGCTT CTAACGGCCCATGGTAGGC & HindIII & \\
\hline \multirow[t]{2}{*}{11} & p3XFlag-CMV & ALDH7A1 & $\mathrm{F}^{\prime}$ & TGACGATGACAAGCTT ATGTGGCGCCTTCCTCGC & HindIII & 1620 \\
\hline & & & $\mathrm{R}^{\prime}$ & TCGCGGCCGCAAGCTT TTACTGAAACTTGATTCC & HindIII & \\
\hline \multirow[t]{2}{*}{12} & p3XFlag-CMV & ALDH9A1 & $\mathrm{F}^{\prime}$ & TGACGATGACAAGCTT ATGTTTCTCCGAGCAGGC & HindIII & 1557 \\
\hline & & & $\mathrm{R}^{\prime}$ & TCGCGGCCGCAAGCTT TCAAAAAGCAGATTCCACATC & HindIII & \\
\hline \multirow[t]{2}{*}{13} & p3XFlag-CMV & ALDH1L1 & $\mathrm{F}^{\prime}$ & TGACGATGACAAGCTT ATGAAGATTGCAGTGATTG & HindIII & 2709 \\
\hline & & & $\mathrm{R}^{\prime}$ & TCGCGGCCGCAAGCTT TCAGTATTCGAAGGTCAC & HindIII & \\
\hline 14 & p3XFlag-CMV & ALDH1L2 & $\mathrm{F}^{\prime}$ & TGACGATGACAAGCTT ATGCTGCGGCGGGGCAGC & HindIII & 2772 \\
\hline
\end{tabular}

Abbreviations: ALDH, aldehyde dehydrogenase.

phenformin potentiates the induction of G1 and G2 arrest, which induces cell death in NSCLC cell lines (Figure 5). Therefore, gossypol increases the therapeutic response of NSCLC to phenformin (Figure 5) and may provide a novel therapeutic approach for treating NSCLC.

\section{CONFLICT OF INTEREST}

The authors declare no conflict of interest.

\section{ACKNOWLEDGEMENTS}

This work was supported by a research grant from the National Cancer Center of Korea to DH, HJ, KMH and SYK (NCC1410670). CL was supported by an NRF Multi-Omics Program

(2012M3A9B9036679).

1 Pao W, Chmielecki J. Rational, biologically based treatment of EGFR-mutant non-small-cell lung cancer. Nat Rev Cancer 2010; 10: 760-774.
2 Wong DW, Leung EL, So KK, Tam IY, Sihoe AD, Cheng LC et al. The EML4-ALK fusion gene is involved in various histologic types of lung cancers from nonsmokers with wild-type EGFR and KRAS. Cancer 2009; 115: 1723-1733.

3 Li X, Wan L, Geng J, Wu CL, Bai X. Aldehyde dehydrogenase 1A1 possesses stem-like properties and predicts lung cancer patient outcome. J Thorac Oncol 2012; 7: 1235-1245.

4 Jiang F, Qiu Q, Khanna A, Todd NW, Deepak J, Xing L et al. Aldehyde dehydrogenase 1 is a tumor stem cell-associated marker in lung cancer. Mol Cancer Res 2009; 7: 330-338.

5 Cancer Genome Atlas Research N, Weinstein JN, Collisson EA, Mills GB, Shaw KR, Ozenberger BA et al. The Cancer Genome Atlas Pan-Cancer analysis project. Nat Genet 2013; 45: 1113-1120.

6 Sweet S, Singh G. Accumulation of human promyelocytic leukemic (HL-60) cells at two energetic cell cycle checkpoints. Cancer Res 1995; 55: 5164-5167.

7 Sweet S, Singh G. Changes in mitochondrial mass, membrane potential, and cellular adenosine triphosphate content during the cell cycle of human leukemic (HL-60) cells. J Cell Physiol 1999; 180: 91-96.

8 Januchowski R, Wojtowicz K, Zabel M. The role of aldehyde dehydrogenase (ALDH) in cancer drug resistance. Biomed Pharmacother 2013; 67: 669-680.

9 Ma I, Allan AL. The role of human aldehyde dehydrogenase in normal and cancer stem cells. Stem Cell Rev 2011; 7: 292-306. 
10 Kastan MB, Schlaffer E, Russo JE, Colvin OM, Civin Cl, Hilton J. Direct demonstration of elevated aldehyde dehydrogenase in human hematopoietic progenitor cells. Blood 1990; 75: 1947-1950.

11 Deng S, Yang X, Lassus H, Liang S, Kaur S, Ye Q et al. Distinct expression levels and patterns of stem cell marker, aldehyde dehydrogenase isoform 1 (ALDH1), in human epithelial cancers. PLOS ONE 2010; 5: e10277.

12 Kohn FR, Landkamer GJ, Manthey CL, Ramsay NK, Sladek NE. Effect of aldehyde dehydrogenase inhibitors on the ex vivo sensitivity of human multipotent and committed hematopoietic progenitor cells and malignant blood cells to oxazaphosphorines. Cancer Res 1987; 47: 3180-3185.

13 Burgos C, Gerez de Burgos NM, Rovai LE, Blanco A. In vitro inhibition by gossypol of oxidoreductases from human tissues. Biochem Pharmacol 1986; 35: 801-804.

14 Koppaka V, Thompson DC, Chen Y, Ellermann M, Nicolaou KC, Juvonen RO et al. Aldehyde dehydrogenase inhibitors: a comprehensive review of the pharmacology, mechanism of action, substrate specificity, and clinical application. Pharmacol Rev 2012; 64: 520-539.

15 Rekha GK, Sladek NE. Inhibition of human class 3 aldehyde dehydrogenase, and sensitization of tumor cells that express significant amounts of this enzyme to oxazaphosphorines, by the naturally occurring compound gossypol. Adv Exp Med Biol 1997; 414: 133-146.

16 Kitada S, Leone M, Sareth S, Zhai D, Reed JC, Pellecchia M. Discovery, characterization, and structure-activity relationships studies of proapoptotic polyphenols targeting B-cell lymphocyte/leukemia-2 proteins. J Med Chem 2003; 46: 4259-4264.

17 Moretti L, Li B, Kim KW, Chen H, Lu B. AT-101, a pan-Bcl-2 inhibitor, leads to radiosensitization of non-small cell lung cancer. J Thorac Oncol 2010; 5: 680-687.
18 Ren T, Shan J, Qing Y, Qian C, Li Q, Lu G et al. Sequential treatment with AT-101 enhances cisplatin chemosensitivity in human non-small cell lung cancer cells through inhibition of apurinic/apyrimidinic endonuclease 1-activated IL-6/STAT3 signaling pathway. Drug Des Dev Ther 2014; 8: 2517-2529.

19 Van Poznak C, Seidman AD, Reidenberg MM, Moasser MM, Sklarin N, Van Zee $\mathrm{K}$ et al. Oral gossypol in the treatment of patients with refractory metastatic breast cancer: a phase I/II clinical trial. Breast Cancer Res Treat 2001; 66: 239-248.

20 Ready N, Karaseva NA, Orlov SV, Luft AV, Popovych O, Holmlund JT et al. Double-blind, placebo-controlled, randomized phase 2 study of the proapoptotic agent AT-101 plus docetaxel, in second-line non-small cell lung cancer. J Thorac Oncol 2011; 6: 781-785.

21 Guo Q, Liu Z, Jiang L, Hu T, Li D, Liu Y et al. Starvation-induced autophagy in cultured non-small cell lung cancer cells. Nan Fang Yi Ke Da Xue Xue Bao 2014; 34: 627-630.

(c) (i) (2) $\odot$ This work is licensed under a Creative Commons Attribution-NonCommercial-NoDerivs 4.0 Inter-

national License. The images or other third party material in this article are included in the article's Creative Commons license, unless indicated otherwise in the credit line; if the material is not included under the Creative Commons license, users will need to obtain permission from the license holder to reproduce the material. To view a copy of this license, visit http://creativecommons.org/licenses/by-nc-nd/4.0/ 